\title{
Predator sound playbacks reveal strong avoidance responses in a fight strategist baleen whale
}

\author{
Charlotte Curé ${ }^{1,2, *}$, Lise Doksæeter Sivle ${ }^{3}$, Fleur Visser $^{4,5}$, Paul J. Wensveen $^{2}$, \\ Saana Isojunno ${ }^{2}$, Catriona M. Harris ${ }^{6}$, Petter H. Kvadsheim ${ }^{7}$, Frans-Peter A. Lam ${ }^{8}$, \\ Patrick J. O. Miller ${ }^{2}$ \\ ${ }^{1}$ CEREMA - DTer Est, Acoustics Group, 67035 Strasbourg Cedex 2, France \\ ${ }^{2}$ Sea Mammal Research Unit, Scottish Oceans Institute, University of St Andrews, St Andrews, Fife KY16 8LB, UK \\ ${ }^{3}$ Institute of Marine Research (IMR), PO Box 1870, Nordnes, 5817 Bergen, Norway \\ ${ }^{4}$ Kelp Marine Research, Loniusstraat 9, 1624 CJ, Hoorn, The Netherlands \\ ${ }^{5}$ Behavioural Biology Group, Leiden University, PO Box 9505, 2300 RA, Leiden, The Netherlands \\ ${ }^{6}$ Centre for Research into Ecological and Environmental Modelling, Buchanan Gardens, University of St Andrews, \\ St Andrews, Fife KY16 9LZ, Scotland, UK \\ ${ }^{7}$ Norwegian Defence Research Establishment (FFI), 3191 Horten, Norway \\ ${ }^{8}$ Netherlands Organisation for Applied Scientific Research (TNO), PO Box 96864, The Hague, 2509 JG, The Netherlands
}

\begin{abstract}
Anti-predator strategies are often defined as 'flight' or 'fight', based upon prey anatomical adaptations for size, morphology and weapons, as well as observed behaviours in the presence of predators. The humpback whale Megaptera novaeangliae is considered a 'fight' specialist based upon anatomy and observations of grouping behaviour and active defence when attacked by killer whales. However, the early stage of humpback whale anti-predator strategy, when the prey detects the presence of a distant potential predator that may not have perceived it, has never been described. Our aim was to experimentally examine this initial stage of anti-predator responses. Humpbacks are likely to hear well at the frequencies of killer whale vocalisations, thus the perception of killer whale sounds could trigger anti-predator responses. To address this hypothesis, we played mammal-eating killer whale sounds to 8 solitary or paired humpback whales in North Atlantic feeding grounds and monitored their behavioural responses. We found that predator sound playbacks induced a cessation of feeding, a change in the diving pattern and a clear directional and rapid horizontal avoidance away from the speaker. Interestingly, in mothercalf pairs with young calves, the directional horizontal avoidance was atypically alternated by 90 degree turns, which may serve as a mechanism to better track the predator or a stealth tactic when more vulnerable animals are present. These results provide experimental evidence that humpback whales can exhibit a strong horizontal avoidance as an initial stage of anti-predator defence, indicating that anti-predator responses may be more graded and mixed than previously recognized.
\end{abstract}

KEY WORDS: Anti-predator strategy $\cdot$ Predator sound playbacks $\cdot$ Multi-sensor tag $\cdot$ Behavioural responses $\cdot$ Horizontal avoidance $\cdot$ Baleen whale $\cdot$ Humpback whale

\section{INTRODUCTION}

Anti-predator strategies are often grouped as 'fight' versus 'flight' based upon prey species' anatomy (morphology and size), physiological capabilities and behaviour (DeWitt et al. 1999, Lingle \& Pellis 2002). The flight strategy consists of moving rapidly away from the predator whereas the fight strategy consists of active defence to struggle, intimidate and/or discourage the predator. Prey species are classically 
categorized into 1 of these 2 anti-predator strategies because behavioural responses to predators are usually consistent across individuals within species (Frid \& Dill 2002), although substantial variations in the nature or magnitude of responses can be observed across populations and individuals within species depending upon ecological (e.g. availability of refuges), contextual (e.g. presence of congeners in the area) or individual (e.g. body condition, gender) factors (Lingle \& Pellis 2002, Roth \& Johnson 2004, Wasson \& Lyon 2005). Moreover, individuals between and within species can use different anti-predation tactics depending upon their evaluation of the level of predation risk, e.g. identity (species) of the predator, predator group size, predator range and/or predator motivation (Lima \& Dill 1990). Since a hunt passes through an escalating level of predation risk over time, one can expect a variation in the anti-predator behaviour across the different stages of a hunt (Hemmi \& Pfeil 2010). The classification of an animal species into the categories of fight versus flight anti-predator strategies only takes into account the attack phase of predator encounter, when both prey and predator have mutually detected each other and when the predator is already chasing or attacking the prey. However, all other stages of anti-predator responses have the potential for additional and mixed strategies. For instance, at an early stage of the predatorprey interaction, when the prey has detected the predator but when the predator has not yet engaged the hunt, the prey may exhibit a variety of behaviours such as fleeing, 'freezing' or hiding in order to avoid the probability of being detected.

Killer whales can predate on a variety of prey including cetacean species (Reeves et al. 2007, Foote et al. 2009, de Bruyn et al. 2013, Vongraven \& Bisther 2013). Predator-prey interactions involving cetaceans tend to be difficult to observe and are thus poorly known, especially in comparison with interactions involving terrestrial predators and prey. In particular , anti-predator behaviours of large cetaceans such as baleen whales are mostly based upon opportunistic observations and have not been evaluated rigorously. Cetacean anti-predator strategies have been divided into the 2 classic 'fight' and 'flight' categories based upon their anatomy and a wide range of observations of anti-predator behaviours (Ford \& Reeves 2008). Fight anti-predator strategist species have been observed exhibiting active defence behaviours such as the sea-surface rolling and tail fluke splashing of grey whales defending their calves (Ford \& Reeves 2008) or the mobbing behaviour of pilot whales, which increase group size and swim towards killer whales in order to chase them away (Curé et al. 2012, De Stephanis et al. 2014). In large whales (baleen whales, sperm whales), the fight strategy is usually characterized by a coordinated group defence (Curé et al. 2013) and a potential retreat into shallow waters providing a refuge and an advantage in defence (Ford \& Reeves 2008). The flight strategy, on the other hand, does not involve any physical defence behaviours to repel the predator. Deep-diving species such as beaked whales may use a vertical escape strategy by going to or staying at great depths while refraining to vocalise (Tyack et al. 2011, Miller et al. 2015). Alternatively, some baleen whale species such as minke and sei whales typically flee horizontally away from killer whales, at high speed and on a straight course (Ford et al. 2005, Ford \& Reeves 2008).

The humpback whale Megaptera novaeangliae is one of the baleen whale species that has been classified as a fight strategist based upon its anatomy, i.e. big size, robust body shape and presence of barnacles that may serve as weapons, and observations of grouping behaviours and active defence when confronted with killer whale attack (Ford \& Reeves 2008, Pitman et al. 2014). However, the initial stage of their anti-predator strategy when they detect the predator that might not yet have perceived them has never been described. Humpback whales migrate seasonally between temperate or high latitude feeding areas in summer and tropical or subtropical breeding grounds in winter (Clapham \& Mead 1999). Their dive profile is typically composed of bouts of very short and shallow dives (<60 s duration; < 8 m depth) separated by longer and deeper dives (Dunlop et al. 2013, Friedlaender et al. 2013). They prey upon krill, fish, pteropods and some cephalopods (Johnson \& Wolman 1984). As a baleen whale, humpbacks are specialized in filtering prey from the water (Simon et al. 2012). As a rorqual, they show an efficient and sophisticated foraging technique called 'lunge feeding', in which the whale accelerates forward in a burst of energetic fluke strokes prior to a single mouthful engulfment of prey-laden water (Goldbogen et al. 2006, Goldbogen 2010, Friedlaender et al. 2013, L. D. Sivle et al. unpubl). Feeding humpback whales usually mill around within a food-patch area and often exhibit surface-generated behavioural displays such as fluke-ups (raising the fluke out of water) and flipper slaps (Dunlop et al. 2010). On the feeding grounds they forage alone or in small groups where individual associations rarely last longer than a day, except for mother-calf pairs, which remain together (Whitehead 1983, Weinrich \& Kuhlberg 1991). The 
degree to which humpbacks are subject to predation remains uncertain but the regular sightings of scarred individuals and several observations of killer whale attacks indicate that they might be a regular prey target (Jefferson et al. 1991, McCordic et al. 2013), especially calves (Steiger et al. 2008, Pitman et al. 2014). Indeed, observations of attacks by killer whales indicate that they specifically target calves but not single or groups of healthy adults (Ford \& Reeves 2008, Pitman et al. 2014).

Killer whales, like other cetaceans, rely mainly on sound to communicate. Therefore, the interception of their vocalisations by unintended cetacean receivers may inform the eavesdroppers about the presence of predators and induce anti-predator responses at an early stage of a potential predator-prey interaction (Curé et al. 2012, 2013). Hearing sensitivity of the humpback whale, estimated from morphological studies of the basilar membrane, covers the $700 \mathrm{~Hz}$ to $10 \mathrm{kHz}$ band (Houser et al. 2001), overlapping with the frequency range of killer whale vocalisations (500 Hz to $120 \mathrm{kHz}$ ) (Miller 2006, Foote \& Nystuen 2008). Therefore, we expect that the interception of killer whale sounds could potentially mediate changes in humpback whale behaviour and trigger antipredator responses; e.g. inducing the interruption of ongoing activities such as feeding and the exhibition of an anti-predator strategy to remain unnoticed by the killer whales. Humpbacks do not have the physiological capabilities to dive to great depths, as beaked whales do thus a vertical avoidance strategy is not expected. Moreover, humpback whales are not particularly fast swimmers compared to killer whales (Noad \& Cato 2007, Williams \& Noren 2009, which limits their horizontal avoidance capabilities. However, horizontal avoidance may be displayed as an early stage of anti-predator strategy where the purpose would not be to escape from a pursuing predator, but to avoid being detected. Finally, since only groups with calves appear to be attacked by killer whales, we would expect anti-predator behaviours to be substantially different in terms of magnitude and/or nature depending upon the composition of the group and especially whether calves are present or not.

The objective of the present study was to evaluate the anti-predator strategy of humpback whales when they perceive the presence of a distant predator that might not have detected them. We conducted our study in the eastern North Atlantic feeding grounds where humpback whales typically travel and feed alone or in pairs (Kvadsheim et al. 2011, 2012) and where killer whales have been reported to attack baleen whales (McCordic et al. 2013). We simulated predator presence by broadcasting recorded unfamiliar mammal-eating killer whale vocalisations to humpback whales and monitored the behavioural responses of the animals using a high resolution depth-and-sound recording tag (D-tag) and detailed visual observations of the tagged whale's group at the sea surface.

\section{MATERIALS AND METHODS}

\section{General protocol}

Fieldwork was conducted from a research vessel in the northern Norwegian Sea off Spitsbergen during June and July in 2011 and 2012 (Kvadsheim et al. 2011, 2012). The protocol comprised the following phases: (1) tagging operation in which a non-invasive tag was attached to the whale by the means of silicone suction cups; (2) baseline data collection of the tagged animali $_{i}(3)$ sound exposure experiments. Data was collected using D-tags (Johnson \& Tyack 2003) and visual observations (tracking and surface behaviours) until the tag released from the whale. The D-tag was typically programmed to release from the whale after 15-18 h.

One of the 2 small motor-boats carried by the research vessel was launched for tagging operations and then for collecting visual observations of the tagged whales. The second boat was launched for sound playback experiments. Visual observation data were recorded using the software Logger.

\section{D-tag and visual data collection}

We used the depth sensor on the tag (sampled at $50 \mathrm{~Hz}$ ) to investigate potential changes in the dive pattern in response to the sound exposures. The D-tag acoustic recordings (16-bit resolution at 96 or $192 \mathrm{kHz}$ sampling rates) were used for identifying increases in flow noise as part of a lunge detection method (Simon et al. 2012). Using the VHF radio beacon on this tag, we were able to visually track the position of the animal at surfacing events. Visual observations included recording of the position of the tagged whale, and recording of the group size of the tagged whale group and of the presence of surface active behaviours (fluke-up), following the protocol of surface and group behaviour data collection of cetaceans described in Visser et al. (2014). Visual observation data included range and bearing estimates 
used to calculate the whale position and surface behavioural parameters that were recorded at regular 2 min intervals when the tagged whale was present at the surface, or at the first surfacing of the tagged whale following a dive longer than $2 \mathrm{~min}$.

\section{Acoustic stimuli}

Humpback whales were presented with 2 sound stimuli of 15 min duration, broadcasted in a randomized order. One stimulus was a sequence of 'unfamiliar' mammal-eating killer whale sounds (KW) expected to be perceived as an immediate risk of predation (Deecke et al. 2002, Curé et al. 2013). These sounds were previously recorded in the North Pacific using D-tags (Miller et al. 2010) and correspond to natural sequences of calls and clicks produced by the tagged killer whales and by individuals of their group while attacking and feeding prey (group size: 3-4 animals). All stimuli had sections with single calls and sections with overlapping calls coming from different animals of the group. Sound sections that were not part of the killer whale vocalisations, e.g. flow noise (due to swimming speed) and surfacing noise (breathing), were suppressed from the stimuli. Killer whale sounds showed a frequency range of $0.5-120 \mathrm{kHz}$ with most energy distributed between 1 and $2 \mathrm{kHz}$, corresponding to the fundamental frequency of the majority of the calls (Foote \& Nystuen 2008). The other stimulus presented to the whales was a broadband noise $(0.5-10 \mathrm{kHz})$ used as a negative control (CTRL). CTRL stimuli consisted of non-calling periods from the killer whales recordings, amplified to the same root mean square (RMS) power as the killer whale sound stimuli. Detailed of stimuli preparation can be found in Curé et al. 2013.

For both stimulus types (KW and CTRL), 3 different stimulus versions, collected from different acoustic recordings, were used among the tested whales to avoid pseudoreplication (McGregor et al. 1992).

\section{Playback experiments}

Each playback experiment included the transmission of 2 sound stimuli. For each stimulus playback, we defined three 15 min experimental phases: (1) PRE (15 min before), (2) DUR (during) and (3) POST (15 min after) exposures. A mean \pm SEM recovery period of $32.5 \pm 3.5 \mathrm{~min}($ range $=17-52 \mathrm{~min}, \mathrm{n}=8$ ) separated the 2 stimuli playbacks. This recovery period included the $15 \mathrm{~min}$ POST exposure of the first stimulus followed by the 15 min PRE exposure of the second stimulus. In one case (mn11_157a), the recovery period lasted only $17 \mathrm{~min}$, curbing data collection for the PRE exposure phase of the second stimulus (CTRL in this case).

Before being tested with the playback experiment (CTRL and KW), all tagged whales were previously exposed to a standardized sonar exposure protocol as part of a parallel project (Kvadsheim et al. 2011, 2012). The recovery period between the last sonar ping and the start of the playback experiment lasted a minimum of $1 \mathrm{~h}$. CTRL and KW stimuli were transmitted using a M-Audio Microtrack II recorder and amplified by a Cadence Z8000 amplifier connected to a Lubell LL9642T underwater loudspeaker (frequency range: 0.2$20 \mathrm{kHz}$ ) at a depth of $8 \mathrm{~m}$.

To measure the sound level of the source and to ensure that sounds were played back by the system without distortion, playback stimuli were recorded using a calibrated hydrophone placed $1 \mathrm{~m}$ from the source. Acoustic recording equipment used for playback monitoring were either a Bruel and Kjaer 8105 hydrophone amplified by a Bruel and Kjaer 2635 charge amplifier and connected to a M-Audio Microtrack II recorder or a Reson TC4032 hydrophone with built in pre-amplifier, connected to an OWID recorder. The sound pressure level of the killer whale stimuli ranged from 146 to $152 \mathrm{~dB}$ re $1 \mu \mathrm{Pa}$ (mean $\pm \mathrm{SD}$ : $150 \pm$ $2 \mathrm{~dB}$ re $1 \mu \mathrm{Pa}, \mathrm{n}=8$ stimuli) which corresponds to the source level of killer whale vocalisations observed in natural conditions (Miller 2006). The sound pressure level of control stimuli ranged from 145 to $150 \mathrm{~dB}$ re $1 \mu \mathrm{Pa}$ (mean $\pm \mathrm{SD}: 147 \pm 2 \mathrm{~dB}$ re $1 \mu \mathrm{Pa}, \mathrm{n}=8$ stimuli).

At the start of each sound playback, the playback vessel was positioned to the front and side of the tagged whale's travel path, at an approximate distance of $800 \mathrm{~m}$ from the tagged whale (mean $\pm \mathrm{SEM}$, $806 \pm 62 \mathrm{~m}, \mathrm{n}=16$ playback trials).

\section{Measure of the behavioural response}

To investigate whether the behaviour of the tagged humpback whales was altered in response to the sound playbacks, we analysed changes in the following behavioural characteristics: direction and speed of horizontal movement; dive behaviour (dive duration and maximum depth); feeding activity (number of lunges and presence of surface fluke-ups in the focal group); group size and group composition (soli- 
tary versus pairs/mother-calf). For each of the 6 experimental phases (PRE_CTRL, DUR_CTRL, POST CTRL, PRE_KW, DUR_KW and POST_KW), we first calculated the average value of each behavioural parameter except for the horizontal movement direction, group size (maximum value) and group composition (calf presence/absence). Second, we calculated 2 behavioural change scores: (1) the difference between the 15 min DUR and the 15 min PRE experimental phases, reflecting the behavioural change induced during the sound exposure (change score PRE_DUR) and (2) the difference between the $15 \mathrm{~min}$ POST and the 15 min PRE exposure periods, indicating whether the behavioural change lasted (or eventually started) after the end of exposure (change score PRE_POST).

Quantification of the change in horizontal direction of movement and speed

A movement reaction score was defined to identify horizontal attraction (positive score) or avoidance (negative score) responses of the tagged animals occurring during the exposure (DUR phase). The method to calculate this reaction score is based on the measure of the distance between the tagged whale position and the sound source (playback vessel) as detailed in Curé et al. (2012). In short, the score is the difference between the actual distance observed at the end of playback and the distance calculated from the projected course of the whale if the whale had kept its direction of horizontal movement just prior to the playback (i.e. direction based on the sightings of the 15 min period preceding the start of playback).

Horizontal speed was calculated as the ratio between the distance and time between 2 successive sightings of the whale at the surface. Therefore, each sighting was assigned a speed value based on the position of the previous sighting.

We occasionally lost track of the tagged whale for short periods. The horizontal movement reaction score and horizontal speed PRE_DUR change score could only be calculated for whales for which we recorded sightings during PRE and DUR exposure phases ( $\mathrm{n}=6$ tagged whales for CTRL playback and $\mathrm{n}=7$ for KW playback). Similarly, the horizontal speed PRE_POST change score could be calculated only for whales for which we recorded sightings during both PRE and POST exposure phases ( $\mathrm{n}=6$ tagged whales for CTRL playback and $n=7$ for KW playback).

\section{Quantification of the change in dive behaviour}

Vertical movements of the tagged animal were analysed using Matlab software (v.7.8.0). We defined a dive as any time the tag was submerged below a depth of $1 \mathrm{~m}$. For each analysed dive, we measured the dive duration (time from start of submerging to the following surfacing) and the maximum depth.

We inspected the frequency distribution of maximum dive depth for all analysed dives (see Fig. S1 in the Supplement at www.int-res.com/articles/suppl/ m526p267_supp.pdf). This analysis showed a dive distribution with one peak at 1-3 m depth and one peak at 21-23 $\mathrm{m}$ depth, but very few dives were recorded within the 15-19 $\mathrm{m}$ depth bins. Based on this, dives were divided into 2 categories: the shallow dive category $(<20 \mathrm{~m} ; \mathrm{n}=601)$ and the deep dive category ( $\geq 20 \mathrm{~m} ; \mathrm{n}=120)$. For each experimental phase $(n=6)$, we analysed on average $( \pm$ SD) $100 \pm 19$ shallow dives (range: 82-126) and $20 \pm 7$ deep dives (range: $11-28)$ ( $\mathrm{n}=8$ tagged whales).

For both shallow and deep dive types we calculated the PRE_DUR and PRE_POST change scores for dive duration and dive depth by subtracting the average value for the PRE phase from the average value of both the DUR and POST phases respectively.

\section{Quantification of the change in foraging behaviour}

To be able to investigate whether the playback sounds altered the foraging behaviour of the whales, the exhibition of foraging cues before the start of a playback (PRE exposure phase) was required. Therefore, we conducted the analyses of the changes (PRE_DUR and PRE_POST) in foraging behaviour only for the subset of experiments for which whales were lunging and/or displaying surface fluke-ups during the 15 min PRE exposure phase.

We investigated the presence of lunges in all dives with a maximum depth $\geq 5 \mathrm{~m}$ by using the relative drop in flow noise within a short time window when a lunge event occurs (Simon et al. 2012). The acoustic recordings of the D-tags were low-pass filtered using a $500 \mathrm{~Hz}$ Butterworth filter and their RMS levels were calculated using an averaging time of $1 \mathrm{~s}$. Then, they were resampled to $5 \mathrm{~Hz}$ to match the sampling rate of the non-acoustic data. The acoustic signature of a lunge is characterized as a period of increased flow noise lasting several seconds followed by a rapid decrease. Lunges were detected as noise peaks that (1) exceed the $90^{\text {th }}$ percentile (from data where the depth was $>10 \mathrm{~m}$ ) of the flow noise in all dives and 
(2) were followed by at least a $12 \mathrm{~dB}$ drop in flow noise within $5 \mathrm{~s}$. Each potential detected lunge was then inspected (aurally and visually on the spectrogram) and assigned as a real lunge or as a false positive. For each playback session (CTRL or KW), we calculated the number of detected lunges per $15 \mathrm{~min}$ experimental phase (PRE, DUR, POST).

The fluke-up activity (whale raising its fluke at the start of a dive, Corkeron 1995) of the focal group was calculated for each $15 \mathrm{~min}$ experimental phase as the proportion of visual observation records with presence of fluke up dives performed by the tagged whale or individuals of its focal group. The focal group was defined as all individuals more closely associated to the tagged whale and to each other, than to other individuals in the area (Visser et al. 2014).

For both lunge and fluke-up activity, we calculated the PRE_DUR and PRE_POST change scores by subtracting the value of the PRE phase from the DUR and POST phases, respectively.

\section{Change in group size and influence of group composition on the response}

Group size was defined as the best estimate of the number of animals in the focal group, which are all animals more closely associated to the tagged whale and to each other, than to other whales in the area (Visser et al. 2014). Duos of whales were considered a mother-calf pair when a pair was composed of 1 adult-sized and 1 smaller-sized individual remaining closely associated with each other throughout the full tracking record $(>5 \mathrm{~h})$, irrespective of behavioural state, or the presence of other whales. We provide a descriptive analysis of changes in group size and differences in the behavioural responses of mother-calf pairs versus solitary or non-mother-calf pairs of animals. The fine-scale underwater movements of the mother-calf pair where both animals were tagged (mn11_165e and mn11_165f) were inspected in detail by calculating the dead-reckoning tracks (Wilson et al. 2007; assuming a constant speed of $1.5 \mathrm{~m} \mathrm{~s}^{-1}$ ) of the whales over the combined PRE, DUR and POST experimental phases of the playbacks.

\section{Statistical analyses}

The tagged whales were each exposed to 2 sound stimuli. To account for these repeated measures, we used Generalized Estimating Equation (GEE) models, which allow us to specify a blocking unit within which observations can be correlated (Hardin \& Hilbe 2003). The aim of this analysis was to test whether Signal (CTRL and KW), playback Order (1 and 2) and Period (PRE_DUR and PRE_POST) had an effect on the change scores calculated for each of the following 7 response variables: (1-4) dive duration and maximum depth of both shallow and deep dives; (5) horizontal speed; (6) number of detected lunges; and (7) proportion of visual observation records with surface fluke-ups. All 3 covariates (Signal, Order, Period) were included as factor covariates with 2 levels each. For the horizontal movement reaction score, which has no Period, there were only the covariates Signal and Order. Each change score was modeled as a Gaussian response variable. The blocking unit was the tagged whale ID except for the model fitted to the number of lunges where the blocking unit was the focal group ID. This was because we included the data from both tagged whales in the instance where an additional tagged whale was associated to the focal tagged whale and these associated whales cannot be assumed to be behaving independently. As the Sandwich variance estimator can be biased for small sample size (here $\mathrm{N}=8$ focal animals), a Jackknife variance estimator was applied in all GEE models. Statistical analyses were performed using geepack (Carey et al. 2012) in R v.3.0.2 (R Development Core Team 2013).

For all GEE models, we first ran the full model with all candidate explanatory variables including the main effect terms, i.e. Signal, Order and Period, and all 2-way interaction terms (Signal:Order, Signal:Period, Order:Period). For the movement reaction score, the full GEE model only had Signal and Order as potential explanatory variables (Curé et al. 2012). We chose to do hypothesis-based model selection using p-values and backwards selection. The Wald test statistics and p-value for each parameter estimate in a GEE model indicate the significance of the difference between factor levels, and not the contribution of the factor covariate to model fit. Therefore for model selection we used the p-values given by an ANOVA (sequential Wald test) on the fitted model object and we used the p-values for each parameter estimate in the GEE for inference purposes. After fitting each model, an ANOVA was conducted on the fitted model object and the covariate or interaction term with the highest $p$-value was removed and the GEE model rerun. This was repeated until all retained terms in the ANOVA were significant at $5 \%$ level (see Table S1 in the Supplement). If an interaction term (e.g. Signal:Period) was retained in the final model, the contributing main effect terms (Sig- 
nal and Period) had also to be retained (regardless of whether they were significant or not). In such cases, only the interaction term could be interpreted.

We expected to see a significant effect of Signal on the response variable if the whales responded differently to the KW playbacks compared to the CTRL. In addition, we expected a significant Period effect on the response variable (PRE_DUR change scores significantly different from PRE_POST change scores) if animals changed behaviour during the exposure but recovered to baseline behaviour after the end of exposure, or if they changed behaviour during the post exposure.

\section{RESULTS}

We conducted experiments with 8 tagged humpback whales (mn11_157a, mn11_160a mn11_165e, mn12_161a, mn12_164b, mn12_170b, mn12_171a, mn12_180a). Two whales were solitary for the full record (mn11_157a, mn12_161a). Three whales (mn12_171a, mn12_170b, mn12_164b) were initially solitary and were then joined by another smaller whale before the start of playbacks. Each of the 3 other whales was in a stable association with another smaller individual for the full tracking record and therefore, these 3 pairs were defined as potential mother-calf pairs. On 2 occasions, the smaller associated animal was also tagged (mn11_165f, mn12_170a) although it was the larger tagged whale (mn11_165e, mn12_170b) that remained the focal tracked animal for the entire experiment. These 2 additional D-tag data streams were included only in the lunge analysis.

Regarding the visual focal follow data (whale position and surface behavioural data), we sampled on average $( \pm \mathrm{SD}) 5 \pm 2$ sighting records per $15 \mathrm{~min}$ experimental phase $(n=6$ tagged whales $\times 6$ phases +2 tagged whales $\times 5$ phases $=46$ phases $)$. There were no sightings for the PRE_CTRL phase of one tagged whale (mn11_165e) and for the DUR_KW phase of another tagged whale (mn11_160a).

\section{Change in horizontal movement (avoidance or attraction)}

Horizontal tracks of the tagged whales showed that animals carried out a clear directional horizontal avoidance in response to the KW playback (Fig. 1). Results of the sequential Wald test showed that Signal
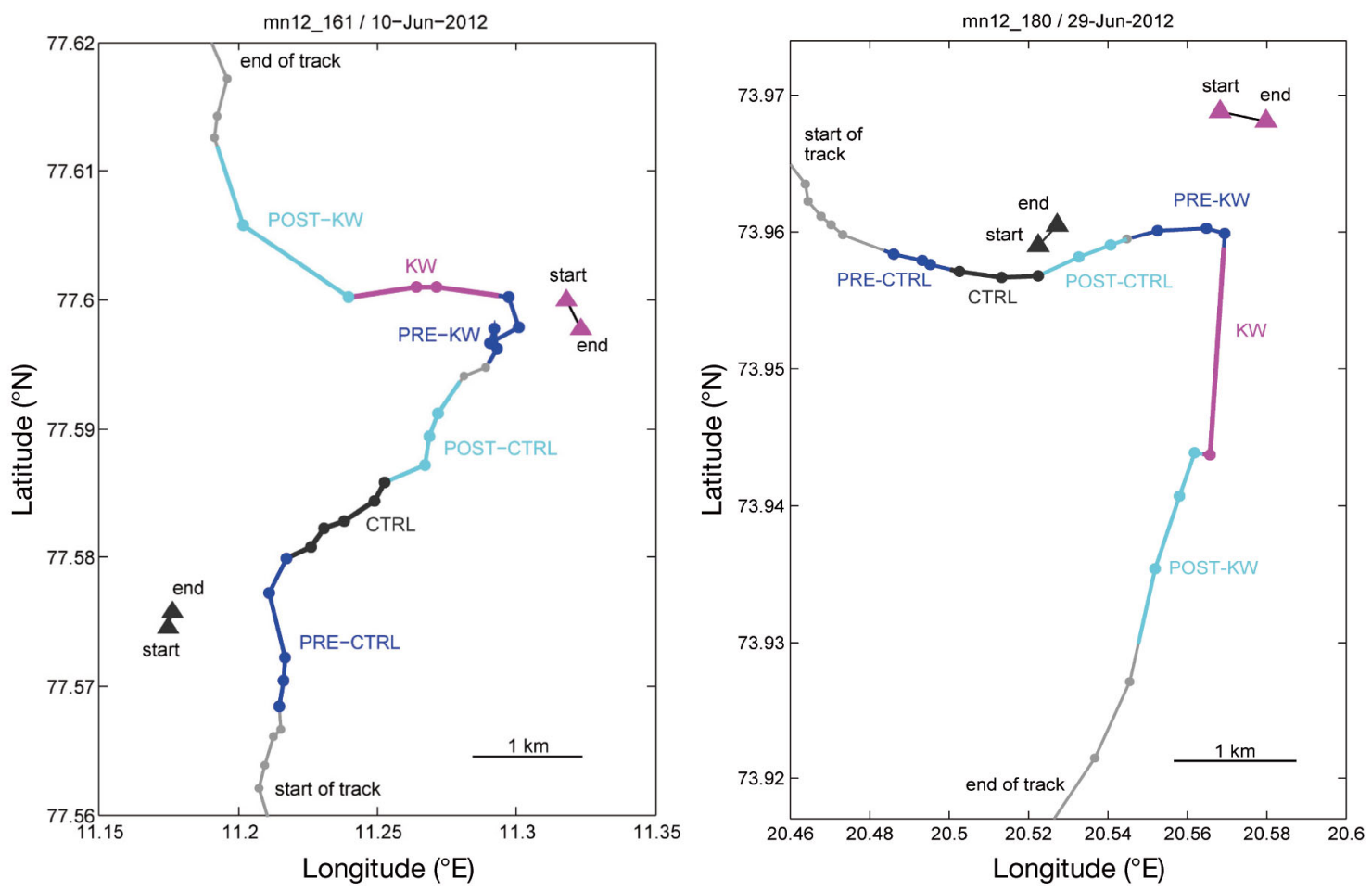

Fig. 1. Horizontal track of tagged humpback whales Megaptera novaeangliae mn12_161a (left) and mn12_180a (right) during control (CTRL; dark grey) and mammal-eating killer whale Orcinus orca (KW; magenta) sound playbacks. The whale track during the PRE and POST exposures is shown in blue and cyan, respectively. Corresponding colour-coded triangles represent the position of the sound source at start and end of playback 
was the only significant variable in explaining the horizontal movement reaction score of the tagged whales (Table S1 in the Supplement). The change of movement direction in response to the CTRL playback was variable among the tested whales $(n=6)$, with 3 whales being attracted towards the sound source (mn11_160a, mn12_170b and mn_12_180a) and 3 whales showing an avoidance response (mn12_161a, mn12_164b and mn12_171a), resulting in a mean reaction score relatively close to zero (Table 1, Figs. 1 \& 2a). In contrast, the KW playback induced a horizontal turn away from the playback speaker in all tagged whales $(\mathrm{n}=7$; Table 1, Figs. 1 \& 2a). The negative mean reaction score of the KW playbacks was significantly different from that of the CTRL regardless of the playback order (GEE: Signal: $p=0.0017$; Table 2).

\section{Change in horizontal speed}

Horizontal speeds calculated for the 6 experimental phases ranged from 0.3 to $2.7 \mathrm{~m} \mathrm{~s}^{-1}$, which

Table 1. Behavioural change scores for killer whale (KW) and control (CTRL) sound playbacks. PRE_DUR = difference between the DUR (sound playback) and PRE phases reflecting the behavioural change induced during the sound exposure; PRE_POST = difference between the POST and PRE phases indicating whether the behavioural change lasted (or eventually started) after the end of exposure); Movement reaction score $=$ horizontal movement reaction score; a.u. = arbitrary units; Fluke-ups = percentage of recorded visual observations with fluke-ups. Values are mean $\pm \mathrm{SD},(\mathrm{N})$, range min; $\max$

\begin{tabular}{|c|c|c|c|c|c|c|c|c|}
\hline & \multirow{2}{*}{$\begin{array}{l}\text { Movement } \\
\text { reaction score } \\
\text { (a.u.) }\end{array}$} & \multirow{2}{*}{$\begin{array}{l}\text { Horizontal } \\
\text { speed } \\
\left(\mathrm{m} \mathrm{s}^{-1}\right)\end{array}$} & \multicolumn{2}{|c|}{ Shallow dives } & \multicolumn{2}{|c|}{ Deep dives } & \multirow{2}{*}{$\begin{array}{l}\text { No. of } \\
\text { lunges }\end{array}$} & \multirow{2}{*}{$\begin{array}{c}\text { Fluke-ups } \\
(\%)\end{array}$} \\
\hline & & & $\begin{array}{l}\text { Duration } \\
\text { (s) }\end{array}$ & $\begin{array}{l}\text { Max. depth } \\
\text { (m) }\end{array}$ & $\begin{array}{l}\text { Duration } \\
\text { (s) }\end{array}$ & $\begin{array}{l}\text { Max. depth } \\
\text { (m) }\end{array}$ & & \\
\hline \multicolumn{9}{|c|}{ KW playback } \\
\hline PRE_DUR & $\begin{array}{c}-63 \pm 29(7) \\
-120.1 ;-33.9\end{array}$ & $\begin{array}{c}0.31 \pm 0.58(7) \\
-0.46 ; 1.12\end{array}$ & $\begin{array}{c}42.5 \pm 33.6(8) \\
1.3 ; 94.4\end{array}$ & $\begin{array}{c}3.1 \pm 1.7(8) \\
0.1 ; 5.0\end{array}$ & $\begin{array}{c}118.7 \pm 91(5) \\
8 ; 285.6\end{array}$ & $\begin{array}{c}7.6 \pm 18.6(5) \\
-15.9 ; 34.2\end{array}$ & $\begin{array}{c}-11 \pm 6(5) \\
-18 ;-1\end{array}$ & $\begin{array}{l}-73 \pm 21(4) \\
-100 ;-50\end{array}$ \\
\hline PRE_POST & - & $\begin{array}{c}0.73 \pm 0.7(7) \\
-0.12 ; 1.70\end{array}$ & $\begin{array}{c}24.9 \pm 34.4(8) \\
-40.1 ; 78.5\end{array}$ & $\begin{array}{c}2.7 \pm 2.0(8) \\
0.2 ; 6.2\end{array}$ & $\begin{array}{c}-7.0 \pm 68.3(5) \\
-97.8 ; 76.8\end{array}$ & $\begin{array}{l}-7.5 \pm 10.2(5) \\
-23.3 ; 1.1\end{array}$ & $\begin{array}{l}-10 \pm 7(5) \\
-18 ;-1\end{array}$ & $\begin{array}{l}-64 \pm 24(4) \\
-100 ;-50\end{array}$ \\
\hline \multicolumn{9}{|c|}{ CTRL playback } \\
\hline PRE_DUR & $\begin{array}{c}17 \pm 62(6) \\
-49.4 ; 122.9\end{array}$ & $\begin{array}{c}0.08 \pm 0.47(6) \\
-0.71 ; 0.62\end{array}$ & $\begin{array}{c}4.33 \pm 9.7(7) \\
-12.1 ; 19.4\end{array}$ & $\begin{array}{c}0.9 \pm 0.9(7) \\
-0.2 ; 2.2\end{array}$ & $\begin{array}{c}-24.1 \pm 36.0(4) \\
-60.4 ; 24.2\end{array}$ & $\begin{array}{l}-2.4 \pm 2.0(4) \\
-3.6 ; 0.5\end{array}$ & $\begin{array}{l}10 \pm 6(4) \\
-6 ; 16\end{array}$ & $\begin{array}{l}-3 \pm 13(3) \\
-17 ; 10\end{array}$ \\
\hline PRE_POST & - & $\begin{array}{c}0.04 \pm 0.40(6) \\
-0.51 ; 0.63\end{array}$ & $\begin{array}{c}3.7 \pm 18.3(7) \\
-11.8 ; 40.1\end{array}$ & $\begin{array}{c}0.4 \pm 3.3(7) \\
-3.9 ; 6.2\end{array}$ & $\begin{array}{c}-43.9 \pm 55.5(4) \\
-98.7 ; 14.4\end{array}$ & $\begin{array}{c}2.8 \pm 12.6(4) \\
-6.2 ; 21.1\end{array}$ & $\begin{array}{l}-3 \pm 13(4) \\
-10 ; 11\end{array}$ & $\begin{array}{l}5 \pm 17(3) \\
-23 ; 10\end{array}$ \\
\hline
\end{tabular}
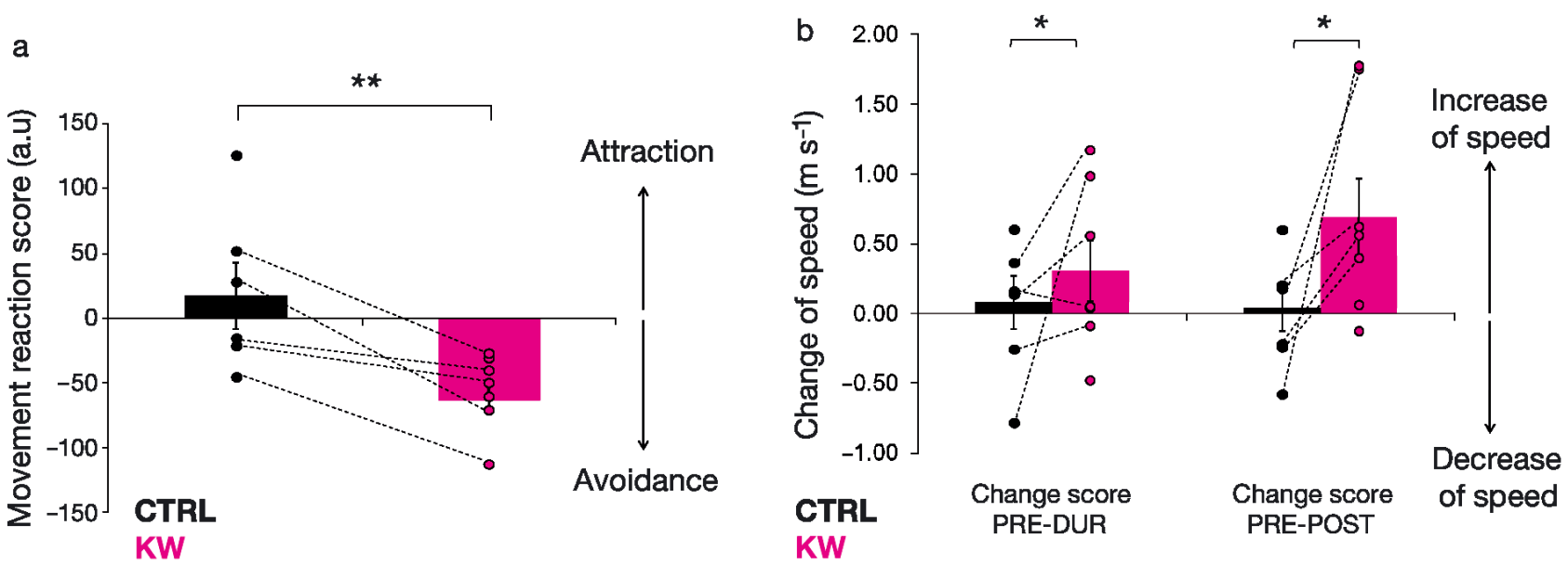

Fig. 2. (a) Horizontal movement reaction score and (b) change of horizontal speed of humpback whales in response to control (CTRL; dark grey) and killer whale (KW; magenta) sound playbacks. The movement reaction score indicates whether the observed direction of horizontal movement during playback (DUR phase) was different compared to the predicted direction of movement if the humpback whale had kept its original (PRE phase) course. The change scores PRE_DUR and PRE_POST of horizontal speed are, respectively, the differences of averaged speed between the DUR and PRE phases and between the POST and PRE phases. Significant differences between CTRL and KW playback are shown, based on GEE results (see Table 2). a.u. = arbitrary units. ${ }^{*} p<0.05,{ }^{* *} p<0.01$ 
is within the specific range of horizontal speeds reported for the species (Ford \& Reeves 2008). All tagged whales increased speed during the DUR or POST phase of the KW playbacks compared to the PRE phase (Fig. 2b, $\mathrm{n}=7$ ): 5 individuals increased speed during KW playback with 4 of them speeding up even more after the end of exposure and 3 individuals increased speed during the POST_KW playback exposure. Results of the sequential Wald test showed that only the interaction term Signal: Order was retained in the best fitting GEE model fitted to the change in horizontal speed (Table S1 in the Supplement). Results of the GEE showed that the whales significantly increased speed in response to KW playbacks compared to the average neutral response to CTRL playbacks (Fig. 2b, Table 1) when KW playback was the second stimulus (GEE: Signal:Order: $p=0.04$, Table 2). In contrast to the clear horizontal swimming acceleration during or after the KW playback by up to $1.70 \mathrm{~m}$ $\mathrm{s}^{-1}$, the speed increase during or after CTRL playback was less than $0.63 \mathrm{~m} \mathrm{~s}^{-1}$ (Fig. 2b, Table 1). The factor Period was not retained in the best fitting model (Table S1 in the Supplement) indicating that the whales kept moving at a relatively high speed during the 15 min following the end of KW playback.

\section{Change in dive behaviour}

For each of the 6 experimental phases, the shallow dives $(<20 \mathrm{~m})$ represented on average $( \pm \mathrm{SD}) 86 \pm 3 \%$ of the total number of dives ( $\mathrm{n}=8$ tagged whales, range: $82-91 \%$ ). The shallow dive type was performed by the 8 tagged whales for each of the 6 experimental phases, whereas the deep dives $(\geq 20 \mathrm{~m})$ were performed only by 4 to 7 tagged whales depending on the experimental phase.

The maximum depth distribution of the DUR_CTRL playback dives appeared close to the distribution of the PRE exposure dives, whereas for the DUR_KW playback, there were fewer 1-3 $\mathrm{m}$ dives and more intermediate (3-19 m) dives (Fig. S2 in the Supplement).

The best fitting model for the change scores of both the duration and maximum depth of shallow dives $(<20 \mathrm{~m})$ only retained Signal (Table S1 in the Supplement). The shallow dives were longer and deeper during the KW playbacks compared to the PRE exposure for all tagged whales, contrasting with the neutral response to the CTRL playbacks (Tables $1 \& 2$ : GEE: Signal: for dive duration: $p=0.00094$; for maxi- mum depth: $\mathrm{p}=0.0027)$. Period was not retained in the best fitting models (Table S1), implying that the dive duration and maximum depth of the shallow dives remained greater during the POST_KW phase compared to the PRE phase.

For deep dives $(\geq 20 \mathrm{~m})$, the interaction term Signal:Period was found to be significant in the best fitting model fitted to the change scores of the duration and maximum depth (Table S1 in the Supplement). Deep dives were significantly longer in the DUR phase than in the PRE phase for KW playbacks compared to CTRL playbacks and this elevation of the dive duration in response to the KW playback did not last after the end of playback (Tables 1 \& 2: GEE: Signal:Period effect: $p=0.048$ ). In addition, dives tended to be deeper during KW playback compared to CTRL playbacks, although the difference was not quite significant at the $\mathrm{p}=$ 0.05 level (Tables 1 \& 2: GEE: Signal:Period: $\mathrm{p}=$ $0.054)$.

The factor Order was not retained in the best fitting models fitted to the change scores of duration and maximum depth of shallow and deep dives (Table S1), indicating that there was no order effect on those behavioural response variables.

\section{Change in feeding behaviour}

Change in the number of lunges

The analysis was conducted on 4 of the 8 focal tagged whales and 2 secondary associated tagged whales (mn12_161a, mn12_164b, mn12_170b, mn12_ 171a, mn11_165f and mn12_170a, respectively).

Only the factor Signal was found to be significant in the best fitting GEE model (Table S1 in the Supplement). All the 5 whales that were lunging before the start of KW playback stopped lunging in the DUR phase of the KW playback and only one (mn12_171a) started to lunge again in the POST phase about $7 \mathrm{~min}$ after the end of KW exposure (Table 1, Fig. 3a,c). In contrast, none of the 4 whales that were lunging before the start of CTRL playback stopped lunging in the DUR and POST phases of the CTRL playback (Table 1, Fig. 3c). This resulted in a significant decrease of lunging activity in response to KW playbacks compared to CTRL playbacks (GEE: Signal: $\mathrm{p}<0.001$, Table 2). Period was not retained in the best fitting model (Table S1 in the Supplement) indicating that the reduction in lunging activity in response to KW playbacks endured also after the end of exposure. 
Table 2. Results of the GEE model fitted to each of the behavioural response variables. Each GEE model was selected based on the results of the ANOVA (see Table S1 in the Supplement at www.int-res.com/articles/suppl/m526p267_supp.pdf).p-values and coefficients are given for each parameter from the selected best fit GEE model; these values represent the difference between the factor levels. In all models the reference level was CTRL for the factor Signal, order 1st for the factor Order and behavioural change from PRE to DUR phases for the factor Period. For response variables for which the fitted GEE model had interaction terms (e.g. Signal:Period) only the p-value and coefficient values for the interaction term (and not the contributing main factors Signal and Period) could be interpreted. The full model for Movement reaction score did not include the factor Period. Movement reaction score $=$ horizontal movement reaction score; Proportion of fluke-ups $=$ proportion of visual observations with fluke-ups; CTRL = control sound playback; PRE_DUR = difference between the DUR (sound playback) and PRE phases reflecting the behavioural change induced during the sound exposure; Order (1st, 2nd) = playback order of 2 phases of sound stimuli (KW followed by CTRL or vice versa); KW = killer whale sound playback; PRE_POST = difference between the POST and PRE phases indicating whether the behavioural change lasted (or eventually started) after the end of exposure. ${ }^{*} \mathrm{p}<0.05,{ }^{* *} \mathrm{p}<0.01,{ }^{* * *} \mathrm{p}<0.001$

\begin{tabular}{|llll|}
\hline Behavioural response & Factor (Reference level) & Response variable coefficients & p \\
\hline Movement reaction score & Signal (CTRL) & KW $=-80.1 \pm 25.5$ & $0.0017^{* *}$ \\
Horizontal speed & Signal (CTRL) & KW $=0.0886 \pm 0.185$ & 0.63 \\
& Order (1st) & 2nd $=0.2121 \pm 0.1820$ & 0.24 \\
& Signal (CTRL):Order (1st) & KW:2nd $=0.6312 \pm 0.3079$ & $0.04^{*}$ \\
Duration of shallow dives & Signal (CTRL) & KW $=29.68 \pm 8.97$ & $0.00094^{* * *}$ \\
Max. depth of shallow dives & Signal (CTRL) & KW $=2.266 \pm 0.756$ & $0.0027^{* *}$ \\
Duration of deep dives & Signal (CTRL) & KW $=142.8 \pm 37.8$ & $0.00016^{* * *}$ \\
& Period (PRE_DUR) & PRE_POST =-19.8 \pm 31.6 & 0.53011 \\
Max. depth of deep dives & Signal (CTRL):Period (PRE_DUR) & KW:PRE_POST $=-105.8 \pm 54.1$ & $0.04805^{*}$ \\
& Signal (CTRL) & KW $=10.056 \pm 7.657$ & 0.1891 \\
No. of lunges & Seriod (PRE_DUR) & PRE_POST $=5.211 \pm 6.022$ & 0.3869 \\
Proportion of fluke-ups & Signal (CTRL) & KW:PRE_POST $=-20.330 \pm 10.546$ & 0.0539 \\
& Signal (CTRL) & KW $=-15.04 \pm 53.27$ & $4.3 \times 10^{-6 * * *}$ \\
& & KW $=-65.90 \pm 8.45$ & $4.1 \times 10^{-10 * * *}$ \\
\hline
\end{tabular}

\section{Change in the proportion of fluke-ups}

This analysis was conducted on the 4 focal pairs (mn11_165e, mn12_170b, mn12_171a, mn12_164b) and the solitary tagged whale (mn11_157a) that were initially exhibiting such surface displays before the start of the playback. Only the factor Signal was retained in the best fitting GEE model fitted to the change in the proportion of visual observation records of the focal group with presence of fluke-ups (Table S1 in the Supplement). Proportion of flukeups was lower during the DUR and POST KW phases compared to the PRE phase (Table 1, Fig. 3a,c). This decrease in the fluking activity was significantly different compared to the neutral response to CTRL playbacks, regardless of playback Order and Period (Table 2: GEE: Signal: $\mathrm{p}<0.001)$. More specifically, KW playbacks induced an interruption of the surface fluke-up activity in all 4 whales (Table 1, Fig. 3a,c). Only 1 tagged whale was recorded fluking up again after the end of KW exposure (Fig. 3c). In contrast, none of the 3 whales that were displaying fluke-ups before the start of CTRL playback stopped fluking up in response to the CTRL playback. Moreover, among the focal groups that were not displaying fluke-up during the PRE phase, 2 started to exhibit a fluke-up activity during the CTRL exposure whereas this never occurred during the KW playback (Fig. 3a). The fact that Period was not retained in the best fitting GEE model (Table S1 in the Supplement) indicated that the decrease in fluke-up activity in response to KW playbacks persisted during the POST KW phase (Table 2).

\section{Change in group size and influence of group composition on the responses}

In all records, the tagged whale was either solitary $(n=2)$, paired with a calf $(n=3)$ or paired with a noncalf animal $(\mathrm{n}=3)$ at the onset of the playback experiment. Among the 3 possible mother-calf pairs, 2 were observed with a small animal that could be identified as a young calf (mn11_165e, mn12_180a).

For the 2 solitary whales, the 3 possible mother-calf pairs, and 2 of the 3 non-mother-calf pairs, group size remained the same for the entire playback experiment (from the PRE-phase of the first playback until 

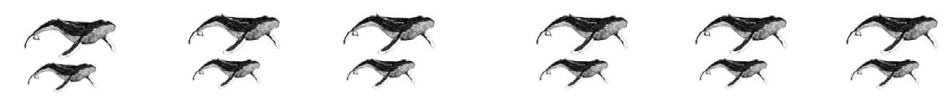

$100 \%$ fluke up

$0 \%$

$0 \%$

$0 \%$

$50 \%$

$0 \%$

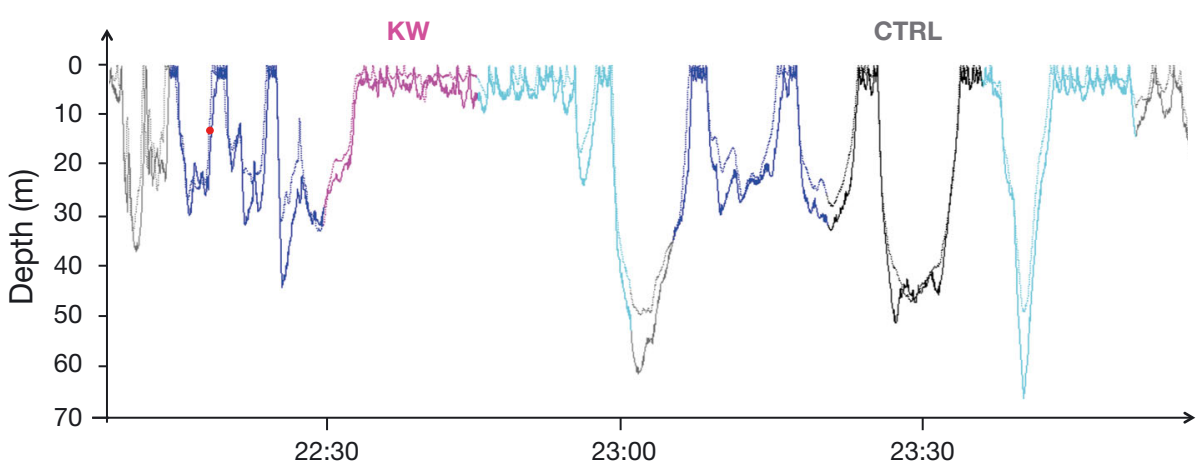

UTC time (h:m)

b

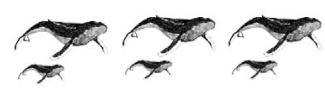

$0 \%$ fluke up $\quad 0 \% \quad 33 \%$

CTRL

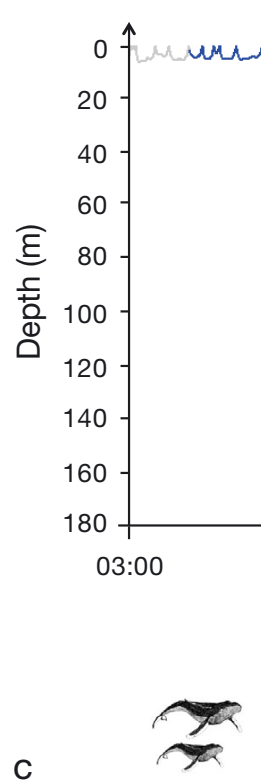

C

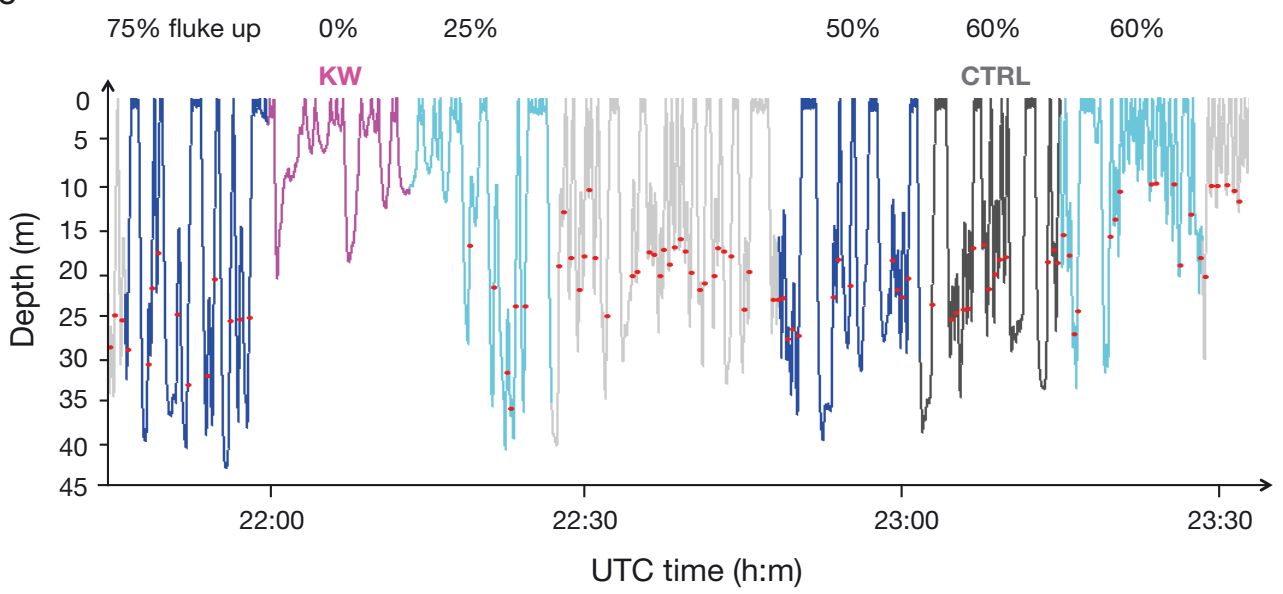

UTC time (h:m)
Fig. 3. Time-depth profile of (a) humpback whale mn11_165e (solid line) and its associated calf mn11_165f (dashed line), and whales (b) mn12_180a and (c) mn12_171a, during control (CTRL; dark grey) and killer whale (KW; magenta) sound playbacks. The PRE and POST exposure phases are shown in blue and cyan, respectively. In (a) and (c), red dots correspond to the detection of a feeding event (lunge). The lunge on panel (a) is from mn11_165f. Group size and proportion of visual observations with presence of surface fluke-ups are represented for each phase (PRE, DUR, POST) at the top of the dive profiles 


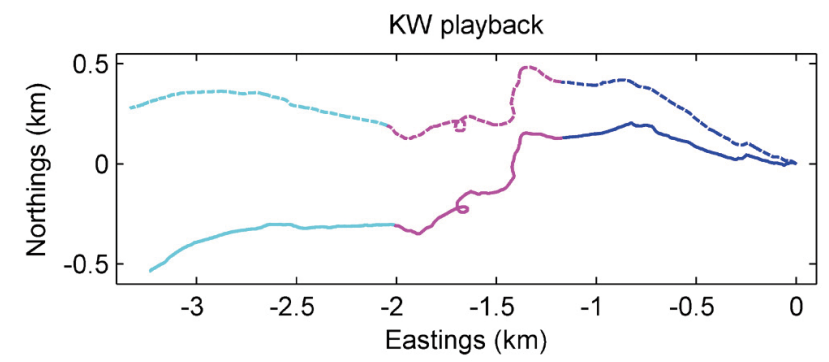

the end of the POST-phase of the second playback). Only in the case of the non-mother-calf pair (mn12_171a) did we observe a change in group size where both associated whales split-up during the KW playback (that was played first), and then remained solitary for the rest of the experiment (Fig. 3c).

The 2 solitary animals (mn11_157a, mn12_161a) were amongst the whales showing the smallest behavioural change scores in response to KW playbacks. The 2 pairs with a young calf (mn11_165e, mn12_180a) showed substantial differences in their responses compared to all other solitary or paired whales. Specifically, the tagged mother mn12_180a responded quite differently with respect to the change in dive pattern compared to all other whales (Fig. 3b). Indeed, this whale conducted its deepest dive $(168 \mathrm{~m})$ in response to the KW playback. In the full $15 \mathrm{~h}$ tag record the animal only once made a dive to a similar depth, which was during the post-tagging phase (i.e. the $30 \mathrm{~min}$ period phase following the end of tagging operation).

Moreover, the 2 mother-calf pairs with small calves showed an unusual horizontal movement pattern during the avoidance response. In one case ( $\mathrm{mn} 12_{-}$ 180a), it became apparent from the visible track of footprints (disturbances) left at the water's surface by the traveling pair that the whales carried out a directional avoidance response from the start of the KW playback. The track of the whales was atypically alternated with a series of four to five 90 degree turns, after which the directional track was continued. Five minutes after the start of KW playback, the adult tagged whale conducted a 9 min deep dive (Fig. 3b) during which the calf also remained unob-

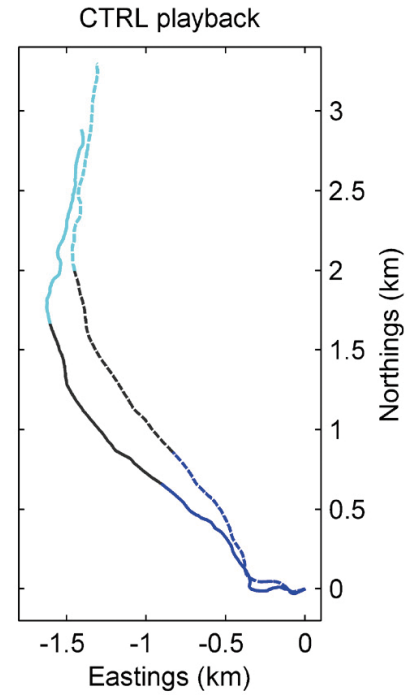

Fig. 4. Fine-scale movements of humpback whale mn11_ 165e (solid line) and its associated calf mn11_165f (dashed line) during killer whale (KW; left) and control (CTRL; right) sound playbacks. These dead-reckoning tracks (Wilson et al. 2007) were created using a forward speed of $1.5 \mathrm{~m} \mathrm{~s}^{-1}$ and are not geo-referenced, therefore the error accumulates over time. The DUR phases of KW and CTRL playback are shown in magenta and dark grey, respectively. The PRE and POST exposure phases are shown in blue and cyan, respectively

served. Then, just after the end of its dive, $1 \mathrm{~min}$ before the end of the KW playback, the mother was seen with its calf and their footprints were seen again, indicating a shallow dive and horizontal cryptic traveling pattern. A similar horizontal movement pattern was observed for the other mother and small calf pair (mn11_165e and calf mn11_165f) during the KW playback where both animals swam at intermediate depths $(<10 \mathrm{~m})$ (Fig. 3a) and travelled with alternating sharp turns and fast directional swimming away from the sound source (Fig. 4). This singular movement pattern was never observed in any of the other whales, or during the CTRL playback.

\section{DISCUSSION}

Our objective was to investigate the early stage of anti-predator responses of humpback whales by exposing them to killer whale sound playbacks that simulated predator presence.

Killer whale sound playbacks strongly changed the behaviour of the 8 tagged humpback whales, indicating that the whales heard the KW sounds. The neutral or weaker response to the playback of a broad band noise (CTRL) stimulus of similar level and frequency range as the KW stimulus, verified that animals responded specifically to the KW sounds and not to any unspecific acoustic stimuli played from the source. The fact that some animals exposed to CTRL playbacks changed their behaviour indicates that the whales also heard the CTRL stimulus.

Prey species are predicted to alter their behaviour in response to the presence of predators by reducing risk activities like feeding and by avoiding the pred- 
ators (Frid \& Dill 2002). Foraging humpback whales interrupted their foraging activity in response to the KW playbacks. More specifically, animals that were initially lunging and/or fluking actively at the surface during the PRE exposure phase stopped showing these feeding-related displays during the KW playback. In contrast, feeding was never interrupted during the CTRL playbacks. Except for 1 whale, cessation of feeding also lasted throughout the $15 \mathrm{~min}$ POST exposure phase of KW playback. Disruption of foraging behaviour is a common reaction of cetacean species exposed to KW sound playbacks (sperm whale: Curé et al. 2013, Blainville's beaked whale: Tyack et al. 2011). The animal's decision to reduce or to stop completely its foraging effort in response to KW playbacks represents a high energy cost that must be explained by the detection of a potential danger. Therefore, KW sound playbacks were likely perceived as a threat by the humpback whales. Additionally, the same humpback whales that were exposed to KW playback were also exposed to naval sonar signals (Kvadsheim et al. 2011, 2012). These signals, in spite of being generated and received at much higher sound pressure level, did not induce reactions as strong as those from the KW playbacks (L. D. Sivle et al. unpubl), indicating that the humpbacks might have interpreted KW sounds as more threatening than potentially unknown louder sounds such as naval sonar signals.

The avoidance response of the humpback whales was characterized by a change in the direction of horizontal movement (away from the underwater loudspeaker) along with a change in the dive pattern. Indeed, most animals switched from the typical diving pattern composed of bouts of very shallow dives (1-3 m) separated by deeper dives (>20 m) to a regular intermediate depth-diving travel mode (3-13 m). This observed horizontal avoidance response of the whales indicates that animals immediately reduced ongoing activity, in favor of a horizontal evasion of the sound source area. Horizontal avoidance responses to killer whale sounds have been demonstrated experimentally in fish (Doksæter et al. 2009), pinnipeds (Deecke et al. 2002) and in both small and large cetacean species such as beluga whales Delphinapterus leucas (Fish \& Vania 1971), grey whales Eschrichtius robustus (Cummings \& Thompson 1971) and sperm whales Physeter macrocephalus (Curé et al. 2013). Our results showed similar anti-predator horizontal avoidance responses in humpback whales. Humpbacks clearly showed a directional horizontal avoidance in response to the killer whale sounds playbacks, swimming away from the speaker and increasing horizontal speed during and/or after the end of exposure (during the $15 \mathrm{~min}$ of post-exposure).

A retreat towards protected cover (e.g. shallow waters or nearby boats) in response to approaching killer whales has been shown, for instance, in narwhals Monodon monoceros (Laidre et al. 2006), and also in 'fight' baleen whale species such as humpback and grey whales (Jefferson et al. 1991, Ford \& Reeves 2008, Pitman et al. 2014). In our study, the avoidance responses of humpback whales were not particularly directed towards a cover or shelter waters. However, the experiments were mostly conducted far from shore (Kvadsheim et al. 2011, 2012) where approaching land would not have been a realistic option for whales to seek refuge.

Becoming silent can be part of the cryptic hunting strategy of mammal-eating killer whales (Deecke et al. 2005) and so the interruption of KW sound playbacks might have been perceived as an increased predation risk, which may explain the increase of speed in the humpback whales after the end of exposure. Interestingly, whales significantly increased horizontal speed when the KW stimulus was played in second order. This order effect might be due to a too small sample size or alternatively to a possible sensitization of the whales by the CTRL stimulus played first, about 30 min earlier.

As observed in terrestrial prey species, anti-predator responses of whale species may vary according to the individual's body condition, gender, age, social status, behavioural state (breeding/foraging), group composition and predatory context (e.g. predator species identity, predator group size, predator range and environmental factors such as availability of refuge). For instance, behavioural responses of migratory humpbacks to the playback of breeding sounds (male songs) can be influenced by different factors such as distance to the sound source, composition of the social group (e.g. calf presence) and received sound level at the start of the playback (Dunlop et al. 2013). Tyack (1983) showed that humpback whale groups with calves exposed to the playback of homospecific social sounds on their breeding grounds avoided the sound source, whereas single animals and most groups without calves exhibited an aggressive behaviour.

Humpback whales, like most animals in general, exhibit stronger and/or different anti-predator responses when they are with calves, because calves are more vulnerable to a lethal attack from a predator (Naessig \& Lanion 2004, Steiger et al. 2008, Pitman et al. 2014). Pitman et al. (2014) studied interac- 
tions between killer whales and humpback whales in humpback breeding grounds off Western Australia. Their observations showed that killer whales only attacked groups of humpbacks with calves and that mothers and/or their accompanying escort actively defended the calf. In contrast, when approaching single adult humpbacks or groups without calf, killer whales never attempted an attack and their approach did not elicit any reaction from the humpback whales. Similarly, in our study, the magnitude of the response to the KW sound playbacks was much lower for the 2 solitary adult animals than for the 3 mother-calf pairs and the 3 pairs between an adult and a younger animal. Moreover, the 2 mother-calf pairs with a young calf exhibited a cryptic horizontal avoidance while shallow swimming, alternating fast directional travel away from the KW sound source and 90 degree turns. This particular movement pattern may serve as a stealth tactic for pairs with a young and vulnerable calf to avoid being detected and/or to confuse the predator. Alternatively, it could be that those 2 pairs were turning to hear or localize the sound source more effectively.

In addition to this cryptic horizontal avoidance, the tagged whale (mn12_180a) associated with a very small calf performed a dive to an unusually large depth $(168 \mathrm{~m})$ during the KW playback, contrasting to the intermediate depth-diving travel of all other tagged whales' responses. It seems that for this particular animal, escaping down to such great depth might have been an additional strategy to remain unnoticed by the killer whales in the presence of a small and more vulnerable animal.

Despite the presence of other humpback whales in the area and the potential social character of the species (Whitehead 1983), the tagged humpback whales did not exhibit a clear social or grouping behaviour during the early stage of anti-predator response when detecting the KW playbacks. One KW playback even induced the break-up of 2 whales, 1 big adult and a smaller adult-sized animal that probably had formed a short-term association with each other. This is in contrast with male sperm whales in the same area, which are normally solitary but grouped when they heard KW vocalisations (Curé et al. 2013). Instead, humpback whales chose to avoid the area by (rapidly) swimming away from the sound source.

The humpback whale is classified as a 'fight species' based on observations of close interactions between humpback whales and killer whales where the predator attack was about to happen or had already been engaged. Those observations likely did not include reactions of humpback whales perceiv- ing the presence of distant killer whales before they perceived their humpback prey. In the present study, we specifically monitored and quantified this early, previously undescribed stage of the anti-predator response of humpback whales. Our findings show that the humpback whale can exhibit strong horizontal avoidance at an early stage of predator encounter. We can't exclude that in a real situation in which killer whales would have attacked the humpback whales, humpbacks would have gradually changed their anti-predator behaviour, switching from an avoidance behaviour to an active physical defence behaviour.

Our results should highlight the importance of considering all stages of anti-predator responses and the influence of contextual factors such as group composition, to fully describe an anti-predator strategy. Anti-predation strategies involve different steps, from an initial response when the prey has detected the presence of a distant potential predator that may not have perceived the prey, to a more advanced stage of the response when the predator attack has already been engaged or is about to happen, therefore representing a higher predation risk level (Hemmi \& Pfeil 2010). This multi-step response might allow prey animals to balance anti-predation costs with the risk of predation. All these anti-predator strategies may vary depending on contextual factors such as group composition where groups with calves, for instance, would be more vulnerable and therefore would exhibit stronger responses than groups of adults with no calves.

Finally, there have also been observations of nonpredatory interactions between killer whales and humpback whales where, for instance, humpback whales non-aggressively approached killer whales that were feeding on sea lions (Dolphin 1987) or between killer whales and other species, where sometimes the prey ignored the predator (Jefferson et al. 1991). Moreover, in the study area, humpback whales have already been reported to feed on herring in close association with killer whales also feeding on herring (L. Kleivane \& P. H. Kvadsheim pers. comm.). A possible explanation for the no or different reaction to their potential predator could be that the prey can discriminate between vocalisations of familiar versus unfamiliar killer whales and also across different killer whale ecotypes (fish versus mammaleating killer whales). Thus, by intercepting KW sounds, humpbacks could be able to evaluate the risk of predation. Here, we used unfamiliar mammal-eating KW sounds associated with feeding behaviour that may represent a higher threat for humpback 
whales compared to other sound types such as familiar fish-eating KW sounds that would likely pose no or less threat to them. However, the present study does not test whether humpback whales would have reacted differently to the playback of familiar and/or fish-eating killer whale sounds. Playback experiments using different artificial and different KW sounds are needed to elucidate these questions, as has been explored in seals (Deecke et al. 2002).

Facing the urgent need to quantify the impacts of anthropogenic noise on cetaceans, the last decades have seen an increasing number of behavioural response studies where animals are exposed to a controlled dose of an acoustic stimulus and their behavioural and/or physiological responses monitored. Those studies would benefit from a theoretical framework for making predictions for understanding why particular responses occur. A model of how animals react in natural conditions when they face a natural threat (e.g. predation risk) could help to guide predictions and to interpret behavioural responses to potential disturbance stimuli in order to establish well balanced mitigation and management decisions (Frid \& Dill 2002, Sih 2013). Anti-predator behaviours of humpback whales in response to the detection of their predator sounds were very consistent among individuals, indicating that they could represent a reliable control for the interpretation of responses to anthropogenic noise.

Acknowledgements. All research activities were licensed under a permit provided by the Norwegian Animal Research Authority (Permit No. S-2011/38782), and were approved by the Animal Welfare Ethics Committee at the University of St Andrews. The Logger software was made available by the International Fund for Animal Welfare. Research funding was provided by the US Office of Naval Research and the Ministries of Defence of Norway, the Netherlands and France, as well as the UK Natural Environmental Research Council. Statistical analyses were supported by the Multi-study OCean acoustics Human effects Analysis (MOCHA) project funded by the United States Office of Naval Research grant N00014-12-1-0204. We are grateful to the many researchers and vessel crew members who helped to collect the data and to Volker Deecke for providing the D-tag acoustic recordings of mammal-eating killer whale sounds. The authors thank Marie Chalandre for providing the whale drawing used in Fig. 3.

\section{LITERATURE CITED}

Carey VJ, Lumley T, Ripley B (2012) gee: Generalized Estimation Equation solver. R package version 4.13-18

> Clapham PJ, Mead JG (1999) Megaptera novaeangliae. Mamm Species 604:1-9

> Corkeron PJ (1995) Humpback whales in Hervey Bay, Queensland: behaviour and responses to whale-watching vessels. Can J Zool 73:1290-1299
Cummings WC, Thompson PO (1971) Gray whales, Eschrichtius robustus, avoid the underwater sounds of killer whales, Orcinus orca. Fish Bull 69:525-530

Curé C, Antunes R, Samarra F, Alves AC, Visser F, Kvadsheim PH, Miller PJO (2012) Pilot whales attracted to killer whale sounds: acoustically-mediated interspecific interactions in cetaceans. PLoS ONE 7:e52201

Curé C, Antunes R, Alves AC, Visser F, Kvadsheim $\mathrm{PH}_{\text {, }}$ Miller PJO (2013) Responses of male sperm whales (Physeter macrocephalus) to killer whale sounds: implications for anti-predator strategies. Sci Rep 3:1579

$>$ de Bruyn PJN, Tosh CA, Terauds A (2013) Killer whale ecotypes: is there a global model? Biol Rev Camb Philos Soc 88:62-80

> De Stephanis R, Giménez J, Esteban R, Gauffier P, GarciaTiscar S, Sinding MHS, Verborgh P (2014) Mobbing-like behavior by pilot whales towards killer whales: a response to resource competition or perceived predation risk? Acta Ethol 18(1):69-78

> Deecke VB, Slater PJB, Ford JKB (2002) Selective habituation shapes acoustic predator recognition in harbour seals. Nature 420:171-173

> Deecke VB, Ford JKB, Slater PJB (2005) The vocal behaviour of mammal-eating killer whales: communicating with costly calls. Anim Behav 69:395-405

DeWitt TJ, Sih A, Hucko JA (1999) Trait compensation and cospecialization: size, shape, and antipredator behaviour. Anim Behav 58:397-407

Doksæter L, Godø OR, Handegard NO, Kvadsheim P, Lam FP, Donovan C, Miller PJO (2009) Behavioral responses of herring (Clupea harengus) to $1-2 \mathrm{kHz}$ sonar signals and killer whale feeding sounds. J Acoust Soc Am 125: 554-564

Dolphin WF (1987) Observations of humpback whale, Megaptera novaeangliae-killer whale, Orcinus orca, interactions in Alaska: comparison with terrestrial predator-prey relationships. Can Field Nat 101:70-75

> Dunlop RA, Cato DH, Noad MJ (2010) Your attention please: increasing ambient noise levels elicits a change in communication behaviour in humpback whales (Megaptera novaeangliae). Proc R Soc Lond B Biol Sci 277:2521-2529

> Dunlop RA, Noad MJ, Cato DH, Kniest E, Miller PJO, Smith JN, Stokes MD (2013) Multivariate analysis of behavioural response experiments in humpback whales (Megaptera novaeangliae). J Exp Biol 216:759-770

Fish JF, Vania JS (1971) Killer whale, Orcinus orca, sounds repel white whales, Delphinapterus leucas. Fish Bull 69: 531-535

Foote AD, Nystuen JA (2008) Variation in call pitch among killer whale ecotypes. J Acoust Soc Am 123:1747-1752

> Foote AD, Newton J, Piertney SB, Willerslev E, Gilbert MTP (2009) Ecological, morphological and genetic divergence of sympatric North Atlantic killer whale populations. Mol Ecol 18:5207-5217

> Ford JKB, Reeves RR (2008) Fight or flight: anti-predator strategies of baleen whales. Mammal Rev 38:50-86

> Ford JKB, Ellis GM, Matkin DR, Balcomb KC, Briggs D, Morton AB (2005) Killer whale attacks on minke whales: prey capture and antipredator tactics. Mar Mamm Sci 21: 603-618

Frid A, Dill LM (2002) Human-caused disturbance stimuli as a form of predation risk. Conserv Ecol 6:11-27

Friedlaender AS, Tyson RB, Stimpert AK, Nowacek DP (2013) Extreme diel variation in the feeding behavior of humpback whales along the western Antarctic Peninsula 
during autumn. Mar Ecol Prog Ser 494:281-289

Goldbogen JA (2010) The ultimate mouthful: lunge feeding in rorqual whales. Am Sci 98:124-131

Goldbogen JA, Calambokidis J, Shadwick RE, Oleson EM, McDonald MA, Hildebrand JA (2006) Kinematics of diving and lunge-feeding in fin whales. J Exp Biol 209: 1231-1244

Hardin JW, Hilbe JM (2003) Generalized estimating equations. Chapman \& Hall/CRC, Boca Raton, FL

$>$ Hemmi JM, Pfeil A (2010) A multi-stage anti-predator response increases information on predation risk. J Exp Biol 213:1484-1489

Houser DS, Helweg DA, Moore PWB (2001) A bandpass filter-bank model of auditory sensitivity in the humpback whale. Aquat Mamm 27:82-91

Jefferson TA, Stacey PJ, Baird RW (1991) A review of killer whale interactions with other marine mammals: predation to co-existence. Mammal Rev 21:151-180

Johnson MP, Tyack PLA (2003) Digital acoustic recording tag for measuring the response of wild marine mammals to sound. IEEE J Oceanic Eng 28:3-12

Johnson JH, Wolman AA (1984) The humpback whale, Megaptera novaeangliae. Mar Fish Rev 46:30-37

Kvadsheim P, Lam FP, Miller PJO, Doksæter L and others (2011) Behavioural response studies of cetaceans to naval sonar signals in Norwegian waters-3S-2011 Cruise Report. FFI-rapport 2011/01289. Forsvarets forskningsinstitutt / Norwegian Defence Research Establishment (FFI), Kjeller. Available at: http://rapporter.ffi.no/ rapporter/2011/01289.pdf

Kvadsheim P, Lam FP, Miller PJO, Wensveen P and others (2012) Behavioural response studies of cetaceans to naval sonar signals in Norwegian waters-3S-2012 Cruise Report. FFI-rapport 2012/02058. Norwegian Defence Research Establishment (FFI), Kjeller. Available at: http://rapporter.ffi.no/rapporter/2012/02058.pdf

Laidre KL, Heide-Jørgensen MP, Orr J (2006) Reactions of narwhals, Monodon monoceros, to killer whale, Orcinus orca, attacks in the eastern Canadian High Arctic. Can Field Nat 120:457-465

Lima SL, Dill LM (1990) Behavioural decisions made under the risk of predation: a review and prospectus. Can J Zool 68:619-640

Lingle S, Pellis SM (2002) Fight or flight? Antipredator behaviour and the escalation of encounters with deer. Oecologia 131:154-164

McCordic JA, Todd SK, Stevick PT (2013) Differential rates of killer whale attacks on humpback whales in the North Atlantic as determined by scarification. J Mar Biol Assoc UK 1:1-5

McGregor PK, Catchpole CK, Dabelsteen T, Falls JB and others (1992) Design of playback experiments. In: McGregor PK (ed) Playback and studies of animal communication. Plenum Press, New York, NY, p 1-9

Miller PJO (2006) Diversity in sound pressure levels and estimated active space of resident killer whale vocalizations. J Comp Physiol A Neuroethol Sens Neural Behav Physiol 192:449-459

Miller PJO, Shapiro AD, Deecke VB (2010) The diving behaviour of mammal eating killer whales (Orcinus orca L., 1758): variations with ecological not physiological factors. Can J Zool 88:1103-1112

Naessig PJ, Lanyon JM (2004) Levels and probable origin of

Editorial responsibility: Peter Corkeron,

Woods Hole, Massachusetts, USA predatory scarring on humpback whales (Megaptera novaeangliae) in east Australian waters. Wildl Res 31: 163-170

Noad MJ, Cato DH (2007) Swimming speed of singing and non-singing humpback whales during migration. Mar Mamm Sci 23:481-495

> Pitman RL, Totterdell JA, Fearnbach H, Balance LT, Durban JW, Kemps H (2014) Whale killers: prevalence and ecological implications of killer whale predation on humpback whale calves off Western Australia. Mar Mamm Sci (in press)

R Development Core Team (2013) R: a language and environment for statistical computing. Version 2.5.0. R Foundation for Statistical Computing, Vienna

Reeves RR, Berger J, Clapham PJ (2007) Killer whales as predators of large baleen whales and sperm whales. In: Estes J (ed) Whaling, oceans and food webs. University of California Press, Berkeley, CA, p 172-186

Roth ED, Johnson JA (2004) Size-based variation in antipredator behaviour within a snake (Agkistrodon piscivorus) population. Behav Ecol 15:365-370

- Sih A (2013) Understanding variation in behavioural responses to human-induced rapid environmental change: a conceptual overview. Anim Behav 85:1077-1088

Simon M, Johnson M, Madsen PT (2012) Keeping momentum with a mouthful of water: behaviour and kinematics of humpback whale lunge feeding. J Exp Biol 215: 3786-3798

Steiger GH, Calambokidis J, Straley JM, Herman LM and others (2008) Geographic variation in killer whale attacks on humpback whales in the North Pacific: implications for predation pressure. Endang Spec Res 4:247-256

> Tyack PL (1983) Differential response of humpback whales, Megaptera novaeagliae, to playback of song or social sounds. Behav Ecol Sociobiol 13:49-55

> Tyack PL, Zimmer WMX, Moretti D, Southall BL and others (2011) Beaked whales respond to simulated and actual navy sonar. PLoS ONE 6:e17009

Visser F, Miller PJO, Antunes R, Oudejans M and others (2014) The social context of individual foraging behaviour in long-finned pilot whales (Globicephala melas). Behaviour 151:1453-1477

> Vongraven D, Bisther A (2013) Prey switching by killer whales in the north-east Atlantic: observational evidence and experimental insights. J Mar Biol Assoc UK 94: $1357-1365$

Wasson K, Lyon BE (2005) Flight or fight: flexible antipredatory strategies in porcelain crabs. Behav Ecol 16: 1037-1041

- Weinrich MT, Kuhlberg AE (1991) Short-term association patterns of humpback whale (Megaptera novaeangliae) groups on their feeding grounds in the southern Gulf of Maine. Can J Zool 69:3005-3011

Whitehead H (1983) Structure and stability of humpback whale groups off Newfoundland. Can J Zool 61: 1391-1397

Williams R, Noren DP (2009) Swimming speed, respiration rate, and estimated cost of transport in adult killer whales. Mar Mamm Sci 25:327-350

Wilson RP, Liebsch N, Davies IM, Quintana F and others (2007) All at sea with animal tracks; methodological and analytical solutions for the resolution of movement. Deep-Sea Res II 54:193-210

Submitted: October 16, 2014; Accepted: February 2, 2015

Proofs received from author(s): April 1, 2015 